\title{
Molecular Characterisation and Profile of Extended Spectrum Beta Lactamase Producing Enterobacteriaceae Isolates Causing Neonatal Sepsis at a Tertiary Care Center
}

\section{Rajesh Kumar', Pankaj Kumar'1, Manoj Kumar Singh', Vivek Singh¹, Sheo Pratap Singh $^{1}$ and Ankur Goyal ${ }^{2}$}

\author{
${ }^{1}$ Department of Paediatrics, S.N. Medical College, Agra, UP, India \\ ${ }^{2}$ Department of Microbiology, S.N. Medical College, Agra, UP, India
}

\section{Correspondence: \\ Dr Rajesh Kumar \\ Department of Paediatrics \\ S.N. Medical College, Agra, UP, India \\ E-mail: drrajesh71@gmail.com}

DOI: $10.3126 /$ jnps.v41i2.31423

Submitted on: $2020-09-23$

Accepted on: 2021-06-27

Acknowledgements: None

Funding: Nil

Conflict of Interest: None declared

Permission from IRB: Yes

To cite this article: Kumar R, Kumar P, Singh MK, Singh V, Singh SP, Goyal A. Molecular Characterisation And Profile Of Extended Spectrum Beta Lactamase Producing Enterobacteriaceae Isolates Causing Neonatal Sepsis at a Tertiary Care Center. J Nepal Paediatr Soc. 2021;41(2):197-204.

\begin{abstract}
Introduction: Emergence of extended spectrum beta-lactamase producing strains of gram-negative bacteria is increasing and it affects outcome of neonatal sepsis. Present study was done to assess the prevalence, antibiogram and molecular characterisation of ESBL producing enterobacteriaceae organisms in neonatal sepsis.
\end{abstract}

Methods: A cross-sectional study was conducted at a tertiary care centre in Agra from January 2016 to June 2017. Total 700 patients satisfying inclusion and exclusion criteria were enrolled. Workup for sepsis screen, blood culture, antibiotic susceptibility, disk approximation test for detection of ESBL producing organism and polymerase chain reaction were performed.

Results: Out of 700 patients, blood culture was positive in 238 (34\%) cases. Among all the blood-culture isolates, Gram - positive, Gram negative and candida species were (54\%), (39\%) and (7\%) respectively. Among gram - negative isolates, Klebsiella (16\%), E. coli (10\%), Pseudomonas (6\%), and Burkholderia (5\%) were isolated. Prevalence of ESBL producing Enterobacteriaceae isolates was 42.42\%. Among ESBL producers 13 were E. Coli and 15 were Klebsiella. ESBL producing bacilli were more common in males $(\mathrm{p}=$ $0.015)$ and out born patients $(p=0.042)$. CNS symptoms were the commonest manifestations (35.71\%). All ESBL producing Klebsiella and $92.3 \%$ of E. coli were resistant to co-amoxyclav. All the ESBL producing Klebsiella and E. coli were sensitive to imipenem and colistin. CTXm gene was the commonest gene present in ESBL producing E. coli (61.54\%) and Klebsiella (26.67\%).

Conclusions: ESBL producing Klebsiella and E. coli were resistant to most of the commonly used antibiotics but they were sensitive to carbapenems and colistin. CTXm gene was the commonest gene, associated with ESBL producing enterobacteriaceae.

Keywords: Blood culture; CTXm gene; Enterobacteriaceae; ESBL; Neonatal sepsis

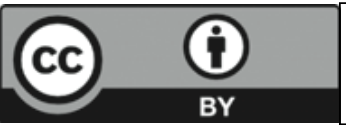

This work is licensed under creative common attribution 3.0 license 


\section{INTRODUCTION}

Neonatal sepsis is a clinical syndrome characterised by signs and symptoms of infection with or without accompanying bacteraemia in the first month of life. It encompasses septicaemia, meningitis, pneumonia, arthritis, osteomyelitis and urinary tract infection. Septicaemia is one of the most important causes of neonatal mortality and morbidity. Incidence of septicaemia varies between countries, but developing countries had reported higher incidence in comparison of developed nations. ${ }^{1}$ In India also many studies had reported septicaemia as a leading cause of neonatal mortality and morbidity. ${ }^{2}$ Both Gram-positive as well as Gramnegative bacteria and sometimes fungal infections are responsible for neonatal sepsis. ${ }^{3}$ Because of the changing pattern of antibiotic use, the spectrum of organisms that cause neonatal sepsis change over times and vary regionally. ${ }^{4}$

Gram negative bacteria form important group of neonatal sepsis worldwide. Among Gram negative bacilli, the two most important bacterial pathogens causing neonatal sepsis in developed countries are Klebisella pneumoniae and E. Coli. ${ }^{5,6}$ Sepsis with extended-spectrum beta-lactamase (ESBL) producing bacteria is a major problem worldwide. ${ }^{7}$ ESBLs are plasmid-mediated enzymes that hydrolyse broad-spectrum beta-lactams. ${ }^{8}$ More than 100 ESBL variants from different types are known, commonest being SHV, TEM, OXA and CTX-M. While TEM- and SHV-type ESBLs have developed from their ancestors SHV-1 and TEM-1/-2 by point mutations, the origin of the other enzymes is less clear. $^{9}$

Molecular characterisation of ESBL from neonatal sepsis cases at Safdarjung Hospital, Delhi had shown CTX-M-15 as the most prevalent type, with other types being TEM-1, SHV-1, SHV-28, SHV-11 and SHV-12. ${ }^{10}$ The present study was planned to know the prevalence and molecular characterisation of extended spectrum beta lactamase producing Enterobacteriaceae in newborns admitted in NICU with neonatal sepsis in our institute.

\section{METHODS}

A cross-sectional, prospective study was carried out among patients admitted with sepsis in NICU in Sarojini Naidu Medical College, Agra, India. All neonates with clinical features suggestive of sepsis like alteration in the established feeding behaviour, tachypnea, chest retraction, grunting, excessive or high pitched cry, seizure, blank look or bulging anterior fontanel, lethargy, hypothermia, fever, diarrhoea, vomiting and abdominal distension, sclerema, episodes of apneic spells or gasping were included in study during January 2016 to June 2017. Neonates who were already on antibiotics or those who developed signs of sepsis within 72 hours of discontinuation of antibiotics, neonates with major congenital anomalies, severe birth asphyxia were excluded. After taking written and informed consent from parents, a semi-structured questionnaire was filled that consisted of basic socio demographic profile. Sepsis screening was carried out in all the newborns. Blood samples were also collected for blood culture and antibiotic sensitivity. The isolates of culture were further analysed for identification of gram negative Enterobacteriaceae and ESBL production. Molecular characterisation of ESBL producers was analysed by PCR.

Neonates with two or more of the following were considered positive sepsis screen - Absolute neutrophil count $<1800$ cell $/ \mathrm{mm}^{3}$, total leucocyte count $<5000 / \mathrm{mm}^{3}$, ratio of immature to total neutrophil count $>0.2$, micro ESR $>15 \mathrm{~mm}$ and $\mathrm{CRP}>10 \mathrm{mg} / \mathrm{l}$. Blood cultures that flagged positive were subjected to Gram staining and sub cultured on appropriate medium. Mac-Conkey agar and 5\% sheep blood agar was used for sub culturing Gramnegative and Gram-positive organisms, respectively. Blood culture bottles incubated in the system for up to seven days.

Antibiotic susceptibility testing was done by Kirby Bauer Disk Diffusion method on Mueller Hinton Agar as per Clinical and Laboratory Standard Institute guidelines (CLSI). Escherichia coli ATCC 25922 was used as control. Samples showing an inhibition zone size of $\leq 22 \mathrm{~mm}$ with ceftazidime and $\leq 27 \mathrm{~mm}$ with cefotaxime were considered as potential ESBL producers and were further investigated for confirmation. ${ }^{11}$ Isolates that showed resistance to third generation cephalosporins were screened to detect ESBL production. A modified double disk synergy (Disk Approximation Test) was carried out on resistant 
isolates. The ESBL producing isolates were further processed for genetic characterisation. Genetic material isolation was done using miniprep (reference) method. ${ }^{11}$

Three sets of primers were used to amplify internal region of the TEM, SHV and CTX-M genes. PCR amplification was performed in $25 \mu \mathrm{l}$ reaction mixture. A negative (no template) control and a positive control containing a DNA mixture of three control strains (SHV-1, TEM-2 and CTX-M betalactamase producers) were included. DNA was amplified with the BIO-RAD $\mathrm{C} 1000^{\mathrm{TM}}$ thermal cycler using 3 cycles. The PCR products were analysed on 2\% Agarose gel with 1U Tris-borateEDTA buffer. The results were confirmed for CTX $_{\mathrm{m}}$, SHV and TEM gene by appearance of band near 544, 928 and 837 base pair marker ladder respectively. Data were presented as frequency and percentage, Chi square test was used to find out association between study groups and $\mathrm{p}$ value $<0.05$ was considered as statistically significant.
Present study was approved by Ethical research committee of the institute.

\section{RESULTS}

Out of 700 cases, sepsis screen was positive in $52.5 \%(\mathrm{n}=368)$ cases and blood culture was positive in $34 \%(\mathrm{n}=238)$ cases (Figure 1). $60.1 \%$ (421) patients were males, $63.9 \%$ (447) were preterm, 65\% (465) were LBW $(<2500$ grams), $47.9 \%$ (335) patients were of lower class, $37.3 \%$ (261) were of lower middle class and $73.4 \%$ (514) were out born. There was statistically significant association of blood culture positivity with sepsis screen, onset of sepsis and place of delivery $(\mathrm{p}<$ 0.05 ) (Table 1). The clinico - pathological features of the cases have been depicted in table 2 .

Among blood culture positive cases $(\mathrm{n}=238)$, Gram-positive bacteria were isolated in $54 \%$, Gram-negative bacteria in 39\% cases and candida in $6.7 \%$ cases. Among Gram - positive bacteria Staphylococcus (31.9\%), Streptococcus (15.1\%), Enterococcus (7.6\%) were isolated. Among Gramnegative bacteria Klebisella pneumoniae (16.8\%),

Table 1. Demographic profile of study population

\begin{tabular}{|c|c|c|c|c|c|}
\hline & & \multicolumn{4}{|c|}{ Blood culture } \\
\hline & & $\begin{array}{c}\text { Total } \\
\mathbf{n}=\mathbf{7 0 0}(\%)\end{array}$ & $\begin{array}{c}\text { Positive } \\
\mathrm{n}=\mathbf{2 3 8}(\%)\end{array}$ & $\begin{array}{c}\text { Negative } \\
n=462(\%)\end{array}$ & p value \\
\hline \multirow[t]{2}{*}{ Gender } & Male & $421(60.1)$ & $148(62.2)$ & $273(59.1)$ & 0.428 \\
\hline & Female & $279(39.8)$ & $90(37.8)$ & $189(40.9)$ & \\
\hline \multirow[t]{2}{*}{ Gestational age } & Preterm & 447 (63.9) & $162(68.1)$ & $285(61.7)$ & 0.096 \\
\hline & Term & $253(36.1)$ & $76(31.9)$ & $177(38.3)$ & \\
\hline \multirow[t]{2}{*}{ Place of delivery } & Inborn & $186(26.6)$ & $77(32.4)$ & $109(23.6)$ & $0.047^{*}$ \\
\hline & Outborn & $514(73.4)$ & $161(67.7)$ & $353(76.4)$ & \\
\hline \multirow[t]{5}{*}{ Socioeconomic status } & Upper class & 0 & 0 & 0 & \\
\hline & Upper middle class & 0 & 0 & 0 & \\
\hline & Middle class & $104(14.8)$ & $33(13.9)$ & $71(15.4)$ & \\
\hline & Lower middle class & $261(37.3)$ & $96(40.3)$ & $165(35.7)$ & \\
\hline & Lower class & $335(47.9)$ & $109(45.8)$ & $226(48.9)$ & \\
\hline \multirow[t]{4}{*}{ Birth weight } & $<1500$ grams & $163(23.3)$ & $60(25.2)$ & $103(22.3)$ & 0.375 \\
\hline & $1500-1999$ grams & $145(20.7)$ & $54(22.7)$ & $91(19.7)$ & \\
\hline & $2000-2499$ grams & $147(21.0)$ & $46(19.3)$ & $101(24.9)$ & \\
\hline & Normal (2500-3999 grams) & $245(35.0)$ & $78(32.8)$ & $167(36.2)$ & \\
\hline \multirow[t]{2}{*}{ Onset of sepsis } & Early onset sepsis & $413(59.0)$ & $153(64.3)$ & $260(56.3)$ & $0.041^{*}$ \\
\hline & Late onset sepsis & $287(41.0)$ & $85(35.7)$ & $202(43.2)$ & \\
\hline \multirow[t]{2}{*}{ Sepsis Screen } & Positive & $368(52.5)$ & $210(88.2)$ & $158(34.2)$ & $<0.001^{*}$ \\
\hline & Negative & $332(47.5)$ & $28(11.8)$ & $304(65.8)$ & \\
\hline
\end{tabular}


Table 2. Clinicopathological profile of study population

\begin{tabular}{|c|c|c|c|c|}
\hline & & $\begin{array}{l}\text { Frequency } \\
(n=700)\end{array}$ & $\begin{array}{c}\text { Culture positive } \\
\text { cases } \\
(n=238)\end{array}$ & $\begin{array}{c}\text { ESBL Positive } \\
\text { Cases } \\
(n=28)\end{array}$ \\
\hline \multirow[t]{7}{*}{$\begin{array}{l}\text { Symptoms and Signs } \\
\text { of sepsis }\end{array}$} & $\begin{array}{l}\text { General symptoms (Refusal to feed, } \\
\text { lethargy) }\end{array}$ & $268(38.28 \%)$ & $96(40.34 \%)$ & $8(28.57 \%)$ \\
\hline & CNS (seizures, bulging fontanels ) & $137(19.57 \%)$ & $53(22.57 \%)$ & $10(35.71 \%)$ \\
\hline & Respiratory symptoms & $132(18.85 \%)$ & $35(14.70 \%)$ & $3(10.71 \%)$ \\
\hline & Hypothermia & $93(13.28 \%)$ & $31(13.03 \%)$ & $2(7.14 \%)$ \\
\hline & $\begin{array}{l}\text { Haematological (Bleeding, } \\
\text { Jaundice) }\end{array}$ & $36(5.14 \%)$ & $10(04.20 \%)$ & $2(7.14 \%)$ \\
\hline & Abdominal distension & $18(2.57 \%)$ & $9(03.78 \%)$ & $3(10.71 \%)$ \\
\hline & Sclerema & $16(2.28 \%)$ & $5(2.10 \%)$ & 0 \\
\hline \multirow[t]{2}{*}{ Onset of sepsis } & Early onset sepsis ( $<72$ hours of life) & $413(59 \%)$ & $153(64.29 \%)$ & $17(60.71 \%)$ \\
\hline & Late onset sepsis ( $>72$ hours of life) & $287(41 \%)$ & $85(35.71 \%)$ & $11(39.29 \%)$ \\
\hline \multirow[t]{2}{*}{ Blood culture } & Positive & $238(34 \%)$ & & \\
\hline & Negative & $462(66 \%)$ & & \\
\hline \multirow{2}{*}{$\begin{array}{l}\text { Total Leucocyte count } \\
\text { (TLC) }\end{array}$} & $<5000$ or $>20000$ per $\mathrm{mm}^{3 *}$ & $154(22 \%)$ & $55(23.11 \%)$ & $9(32.14 \%)$ \\
\hline & $5000-20000$ per $\mathrm{mm}^{3}$ & $546(78 \%)$ & $183(76.89 \%)$ & $19(67.85 \%)$ \\
\hline \multirow{2}{*}{$\begin{array}{l}\text { Absolute neutrophil } \\
\text { counts (ANC) }\end{array}$} & $<1800$ per $\mathrm{mm}^{3 *}$ & $139(19.85 \%)$ & $48(20.17 \%)$ & $7(25 \%)$ \\
\hline & $>1800$ per $\mathrm{mm}^{3}$ & $561(80.15 \%)$ & $190(79.83 \%)$ & $21(75 \%)$ \\
\hline \multirow{2}{*}{$\begin{array}{l}\text { Micro ESR } \\
\text { (Erythrocyte } \\
\text { sedimentation rate) }\end{array}$} & $>15 \mathrm{~mm} *$ & $245(35.00 \%)$ & $92(38.70 \%)$ & $11(39.28 \%)$ \\
\hline & $<15 \mathrm{~mm}$ & $455(65.00 \%)$ & $146(61.30 \%)$ & $17(60.71 \%)$ \\
\hline \multirow[t]{2}{*}{$\mathrm{I} / \mathrm{T}$ ratio } & $>20 \% *$ & $63(09.00 \%)$ & $22(9.24 \%)$ & $4(14.28 \%)$ \\
\hline & $<20 \%$ & $637(91.00 \%)$ & $216(89.02 \%)$ & $24(85.71 \%)$ \\
\hline \multirow{2}{*}{$\begin{array}{l}\text { C- Reactive Protein } \\
\text { (CRP) }\end{array}$} & $>10 \mathrm{mg} / \mathrm{l}^{*}$ & $260(37.15 \%)$ & $98(41.18 \%)$ & $11(39.28 \%)$ \\
\hline & $<10 \mathrm{mg} / \mathrm{l}$ & $440(62.85 \%)$ & $140(58.82 \%)$ & $17(60.71 \%)$ \\
\hline
\end{tabular}

* Taken as Positive

E. Coli (10.9\%), Pseudomonas (6.3\%) and Burkholderia (4.6\%) were isolated.

In our study, isolated organisms of Enterobacteriaceae family (66) were Klebsiella pneumoniae (40) and E. coli (26). Out of 66 culture positive cases of Enterobacteriaceae, 28 (42.42\%) isolates were ESBL producers. Fifty percent $(13 / 26)$ of E. coli and 37.5\% (15/40) of Klebsiella pneumoniae were ESBL producers. ESBL producers were more common in males $(\mathrm{p}=0.015)$ and out born patients $(p=0.042)$ (Table 3$)$. Common clinical and laboratory parameters of babies with ESBL positive sepsis $(n=28)$ has been shown in table 2.

Among ESBL producing E. Coli, eight isolates had $\mathrm{CTX}_{\mathrm{m}}$ gene, two isolates had TEM gene and three isolates had other genes. Among ESBL producing
Klebsiella, four isolates had $\mathrm{CTX}_{\mathrm{m}}$ gene, one isolate had TEM gene, one isolate had SHV gene and nine had other genes (Figure 2). As shown in figure 3, all CTXm ESBL producing E. coli and Klebsiella pneumoniae were resistant to amoxyclav and sensitive to imipenem and colistin. Similar pattern was also seen with TEM positive E coli and Klebsiella pneumoniae isolates and SHV positive Klebsiella pneumoniae isolates, however all the isolates were sensitive to meropenem.

\section{DISCUSSION}

Antibiotic resistance is one of the major concerns in the management of neonatal sepsis and an important confounding factor is the development of ESBL producing organisms. ${ }^{4}$ The most evolving mechanism of ESBL production among Enterobacteriaceae is the selective pressure 
Table 3. Demographic profile of newborns with Enterobacteriaceae isolates

\begin{tabular}{|c|c|c|c|c|c|}
\hline & & \multirow{2}{*}{$\begin{array}{l}\text { Total } \\
\text { Enterobacteriacea } \\
\text { e } n=66(\%)\end{array}$} & \multicolumn{3}{|c|}{ ESBL } \\
\hline & & & $\begin{array}{r}\text { Positive } \\
\mathbf{n}=28(\%)\end{array}$ & $\begin{array}{r}\text { Negative } \\
n=38(\%)\end{array}$ & $P$ value \\
\hline \multirow[t]{2}{*}{ Gender } & Male & $31(47.0)$ & $18(64.3)$ & $13(34.2)$ & $0.015 *$ \\
\hline & Female & $35(53.0)$ & $10(35.7)$ & $25(65.8)$ & \\
\hline \multirow[t]{2}{*}{ Gestational age } & Preterm & $43(65.2)$ & $19(67.9)$ & $24(63.2)$ & 0.692 \\
\hline & Term & $23(34.8)$ & $9(32.1)$ & $14(36.8)$ & \\
\hline \multirow[t]{2}{*}{ Place of birth } & Inborn & $18(27.3)$ & $4(4.3)$ & $14(36.8)$ & $0.042 *$ \\
\hline & Outborn & $48(72.7)$ & $24(85.7)$ & $24(63.2)$ & \\
\hline \multirow[t]{4}{*}{ Birth weight } & $<1500$ grams & $16(24.2)$ & $7(25)$ & $9(23.7)$ & 0.149 \\
\hline & $1500-1999$ grams & $14(21.2)$ & $9(32.1)$ & $5(13.2)$ & \\
\hline & $2000-2499$ grams & $13(19.7)$ & $6(21.4)$ & $7(18.4)$ & \\
\hline & $\begin{array}{l}\text { Normal (2500 - } 3999 \\
\text { grams) }\end{array}$ & $23(34.9)$ & $6(21.4)$ & $17(44.7)$ & \\
\hline \multirow{5}{*}{$\begin{array}{l}\text { Socioeconomic Status } \\
\text { (Modified BG Prasad, } \\
\text { 2016) }\end{array}$} & Upper class & 0 & 0 & 0 & \\
\hline & Upper middle class & 0 & 0 & 0 & $00084 *$ \\
\hline & Middle class & $8(12.12)$ & $3(10.7)$ & $5(13.16)$ & 0.0004 \\
\hline & Lower middle class & $20(30.30)$ & $9(32.1)$ & $11(28.95)$ & \\
\hline & Lower class & $38(57.58)$ & $16(57.2)$ & $22(57.89)$ & \\
\hline \multirow[t]{2}{*}{ Onset of sepsis } & Early onset sepsis & $35(53.0)$ & $17(60.7)$ & $18(63.2)$ & 0.283 \\
\hline & Late onset sepsis & $31(47.0)$ & $11(39.3)$ & $20(63.8)$ & \\
\hline
\end{tabular}

* p value $<0.05$ considered as statistically significant

imposed by inappropriate use of third generation cephalosporins, most often encountered in ICU settings. ${ }^{12}$
In present study neonatal sepsis was found to be more common among males, preterm, outborn and LBW babies and these findings were similar to several other studies. ${ }^{13,14}$ Highest number of

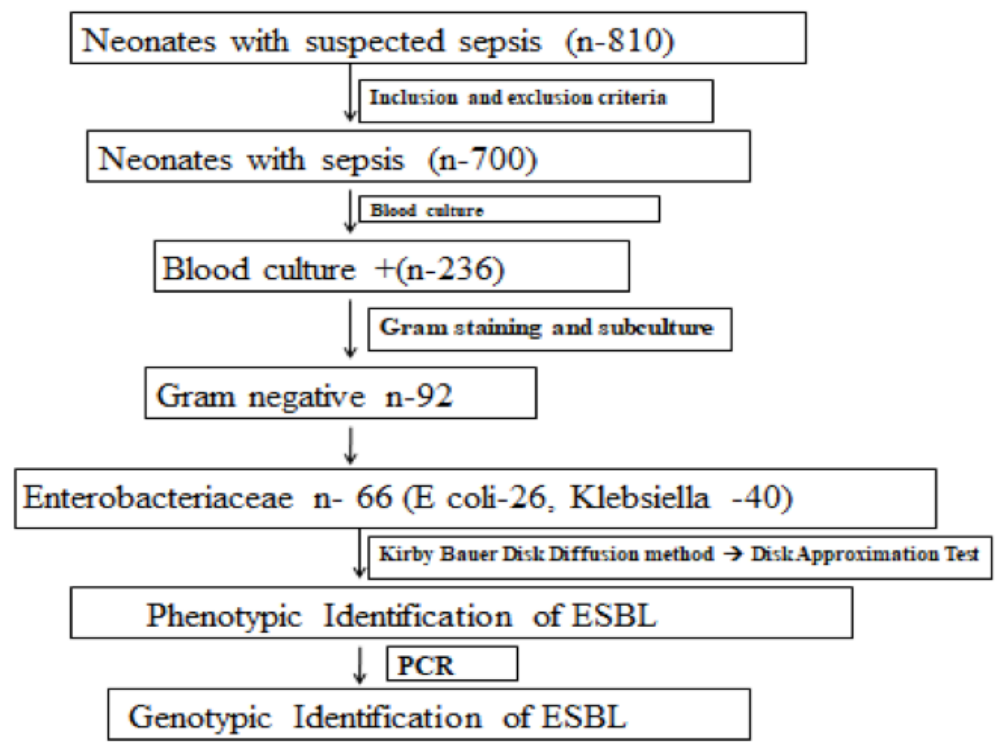

Figure 1. Schematic diagram of study design 


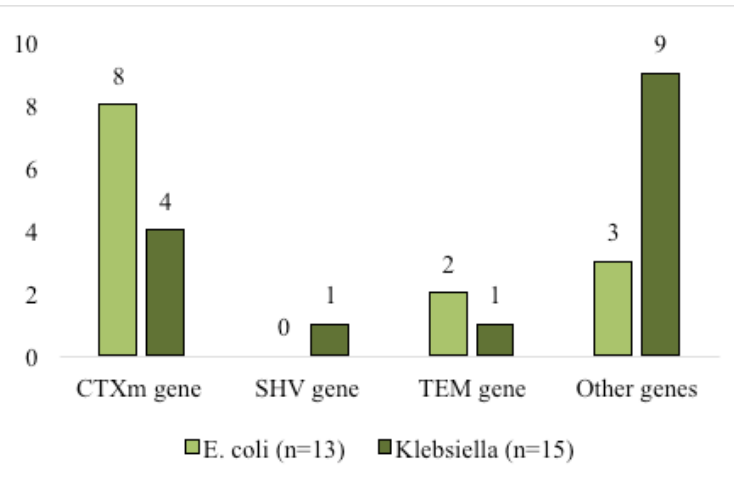

Figure 2. Molecular categorisation of ESBL positive isolates

patients were of lower socio-economic class, as in the study of Ahmed et al. ${ }^{15}$ Most common presenting symptoms were refusal to feed and lethargy, followed by CNS and respiratory manifestation and these findings were similar to several other studies. ${ }^{14,16}$

The results of blood culture in our study were comparable to various other studies. In present study blood culture was positive more in outborn babies $(p=0.047)$, neonates with early onset sepsis $(\mathrm{p}=0.041)$ and in neonates with positive sepsis screen $(\mathrm{p}<0.001) .{ }^{17,18}$ Among culture positive cases gram-positive bacteria were most common isolates. In this group Staphylococcus was most common organism followed by Streptococcus and Enterococcus. Similar results were seen in the study done by Kartikeyanet al. ${ }^{19}$ An ESBL phenotype was recognized in $42.42 \%$ isolates in our study which was similar to the study done by Tofteland et al. ${ }^{20}$ We found that among Gram negative isolates Klebsiella and E. coli were isolated most just like in other studies. ${ }^{5,6}$ Prevalence of ESBL producing E. coli and Klebsiella pneumoniae isolates in our study was similar to various other studies. ${ }^{10,21,22}$ The pattern of ESBL producing E Coli in our study was similar to study by Mardano et al. who noted that neonates having increased age and transferred from other centres had more prevalence of ESBL producing E Coli and significant morality rates. ${ }^{23}$

We found that CTXm gene was the commonest gene present in ESBL producing enterobacteriace

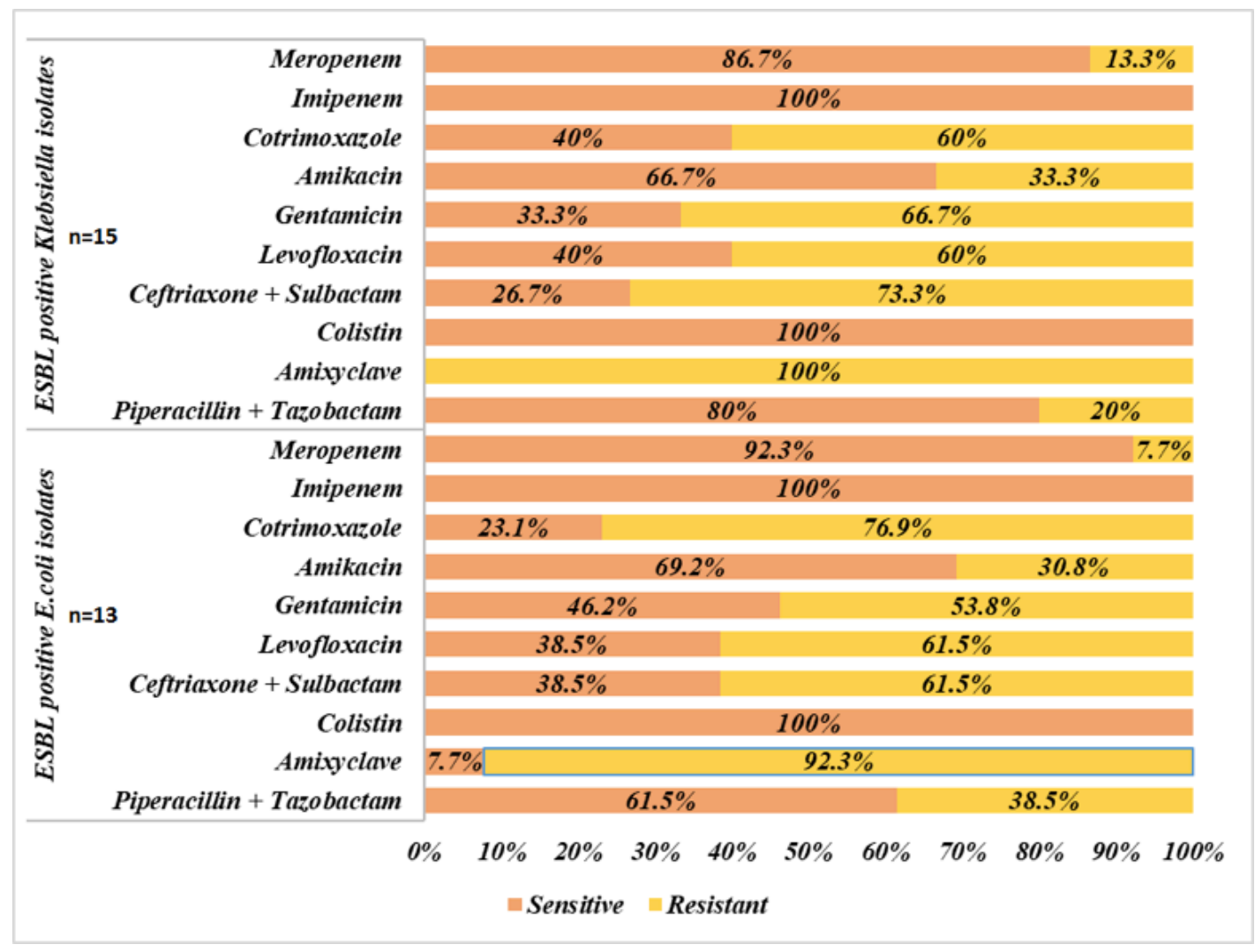

Figure 3. Distribution of cases based on Antibiogram of ESBL Positive isolates 
isolates followed by TEM and SHV gene. CTXm gene was associated with resistance to most of the first line cephalosporins and amikacin and fluroquinolones and sensitive to imipenem, meropenem and pipercillin - tazobactam. ${ }^{10,24}$ This fact is also supported in our study. Several studies have reported that carbapenems along with $\beta$ lactam / $\beta$ lactamase inhibitors combination could be used as empirical therapy for suspicion of ESBL producing bacteria..$^{25,26}$

Although we tried to elaborate the organisms implicated in neonatal sepsis, our study is relatively small and single centric. We also could not identify gene responsible for ESBL production in three cases of ESBL producing $E$. coli and nine cases of ESBL producing Klebsiella because of resource constraints. Despite these limitations, we are hopeful that our research light help to shed more light on the topic of neonatal sepsis in resource limited set up like ours.

\section{CONCLUSIONS}

Among ESBL producers, E. coli and Klebsiella were the commonest organisms isolated and were more prevalent in outborns and male babies. These isolates were resistant to commonly used antibiotics like penicillin, cephalosporines, fluoroquinolons and aminoglycosides and were sensitive to carbapenems and colistin. CTXm gene was most common gene associated with ESBL producing E. coli and Klebsiella.

\section{REFERENCES}

1. Kaistha N, Mehta M, Singla N, Garg R, Chander J. Neonatal septicemia isolates and resistance patterns in a tertiary care hospital of North India. J Infect Dev Ctries. 2009;4:55-7. DOI:10.3855/jidc.625

2. Tsering DC, Chanchal L, Pal R, Kar S. Bacteriological profile of septicemia and the risk factors in neonates and infants in Sikkim. J Glob Infect Dis. 2011;3(1):42-5. DOI: 10.4103/0974-777X.77295

3. Randrianirina F, Vedy S, Rakotovao D, Ramarokoto C-E, Ratsitohaina H, Carod JF, et al. Role of contaminated aspiration tubes in nosocomial outbreak of Klebsiella pneumoniae producing SHV-2 and CTX-M-15 extendedspectrum $\beta$-lactamases. J Hosp Infect. 2009;72(1):23-9. DOI: 10.1016/j.jhin.2009.02.004.

4. Orencia MC, Yoon JS, Ness JE, Stemmer WPC, Stevens RC. Predicting the emergence of antibiotic resistance by directed evolution and structural analysis. Nat Struct Mol Biol. 2001;8(3):238-242. DOI: 10.1038/84981

5. Zaidi AKM, Thaver D, Ali SA, Khan TA. Pathogens associated with sepsis in new born and young infant in developing countries. Pediatr infect Dis J. 2009;28:10-8. DOI: 10.1097/INF.0b013e3181958769

6. Harish BN, Menezes GA, Shekatkr S, Parija SC. Extended-spectrum-beta lactamases producing Klebsiella pneumoniae from blood culture. J Med Microbiol. 2007;56:999-1000. DOI: 10.1099/jmm.0.47072-0

7. Quinn JP, Miyashiro D, Sahm D, Flamm R, Bush K. Novel plasmid-mediated beta-lactamase (TEM-10) conferring selective resistance to ceftazidime and aztreonam in clinical isolates of Klebsiella pneumoniae. Antimicrob Agents Chemother. 1989;33(9):1451-6. DOI: 10.1128/aac.33.9.1451.

8. Jacoby GA, Vacheva-Dobrevsky R. Epidemiology of extended-spectrum $\beta$-lactamases in Sofia, Bulgaria. Eur J Clin Microbiol Infect Dis. 2003;22(6):385-8. DOI: 10.1007/s10096-003-0937-z

9. Schmitt J, Jacobs E and Schmidt H. Molecular characterisation of extended-spectrum beta-lactamases in Enterobacteriaceae from patients of two hospitals in Saxony, Germany. Journal of Medical Microbiology. 2007;56: 241-9. DOI: $10.1099 /$ jmm.0.46670-0.

10. Roy S, Gaind R, Chellani H, Mohanty S, Datta S, Singh AK, et al. Neonatal septicaemia caused by diverse clones of Klebsiella pneumonia and Escherichia coli harbouring blaCTX-M-15. Indian J Med Res. 2013;137(4):791-9. PMID: 23703349

11. Jarlier V, Nicolas M-H, Fournier G, Philippon A. Extended broad-spectrum $\beta$-lactamases conferring transferable resistance to newer $\beta$-lactam agents in Enterobacteriaceae: hospital prevalence and susceptibility patterns. Rev Infect Dis. 1988;10(4):867-78. DOI: 10.1093/clinids/10.4.867. 
12. Kanafani ZA, Mehio-Sibai A, Araj GF, Kanaan M, Kanj SS. Epidemiology and Risk Factors For ExtendedSpectrum-Lactamase- Producing Organisms: A Case Control Study at a Tertiary Care Center in Lebanon. Am J Infect Control 2005;33(6), 326-32. DOI:10.1016/j.ajic.2005.03.009

13. Sathyamurthi B, Leela KV, Narayanababu R, Padmanaban S, Sreedevi S, Sujatha, et al. Clinical and Bacteriological Profile of Neonatal Sepsis in a Tertiary Care Hospital. Int J Sci Study. 2016;4(8):57-60. DOI: 10.17354/ijss/ $2016 / 569$

14. Samayam P, Ravichander B. Clinical features and bacteriological profile of late onset sepsis. Int J Contemp Pediatr. 2017;4(2):361-4. DOI:10.18203/2349-3291.ijcp20170068

15. Ahmed A, Chowdhury M, Hoque M, Darmstadt GL. Clinical and bacteriological profile of neonatal septicemia in a tertiary level pediatric hospital in Bangladesh. Indian Pediatr. 2002;39(11):1034-8. PMID:12466574

16. Noor MK, Shahidullah M, Rahman H, Mutanabbi M. Interleukin-6: a sensitive parameter for the early detection of neonatal sepsis. Bangabandhu Sheikh Mujib Med Univ J. 2009;1(1):1-5. DOI: 10.3329/bsmmuj.v1i1.3687

17. Murty DS, Gyaneshwari M. Blood cultures in paediatric patients: A study of clinical impact. Indian J Med Microbiol. 2007;25(3):220-4. DOI: 10.4103/0255-0857.34762

18. Muley VA, Ghadage DP, Bhore AV. Bacteriological profile of neonatal septicemia in a tertiary care hospital from Western India. J Glob Infect Dis. 2015;7(2):75-7. DOI: 10.4103/0974-777X.154444

19. Karthikeyan G, Premkumar K. Neonatal sepsis: Staphylococcus aureus as the predominant pathogen. Indian J Pediatr. 2001;68(8):715-7. DOI:10.1007/BF02752407.

20. Tofteland S, Haldorsen B, Dahl KH, Simonsen GS, Steinbakk M, Walsh TR, et al. Effects of Phenotype and Genotype on Methods for Detection of Extended-Spectrum--Lactamase-Producing Clinical Isolates of Escherichia coli and Klebsiellapneumoniae in Norway. J Clin Microbiol. 2007;45(1):199-205. DOI: 10.1128/JCM.01319-06

21. Abdel-Hady H, Hawas S, El-Daker M, El-Kady R. Extended-spectrum beta lactamase producing Klebsiella pneumoniae in neonatal intensive care unit. J Perinatol. 2008;28(10):685-90. DOI: 10.1038/jp.2008.73.

22. Zakariya BP, Bhat V, Harish BN, Arun Babu T, Joseph NM. Neonatal sepsis in a tertiary care hospital in South India: bacteriological profile and antibiotic sensitivity pattern. Indian J Pediatr. 2011;78(4):413-7. DOI: 10.1007/ s12098-010-0314-8.

23. Marando R, Seni J, Mirambo MM, Falgenhauer L, Moremi N, Mushi MF, et al. Predictors of the extendedspectrum-beta lactamases producing Enterobacteriaceae neonatal sepsis at a tertiary hospital, Tanzania. Int J Med Microbiol. 2018;308(7):803-11. DOI: 10.1016/j.ijmm.2018.06.012.

24. Pitout JD, Church DL, Gregson DB, Chow BL, McCracken M, Mulvey MR, et al. Molecular epidemiology of CTX-M-producing Escherichia coli in the Calgary Health Region: emergence of CTX-M-15-producing isolates. Antimicrob Agents Chemother. 2007;51:1281-6. DOI: 10.1186/1471-2334-12-149

25. Rodriguez-Bano J, Navarro MD, Retamar P, Picon E, Pascual A. Extended-Spectrum Beta-Lactamases-Red Espanola de Investigacion en PatologiaInfecciosa/Grupo de Estudio de Infeccion Hospitalaria G. Beta-lactam/betalactam inhibitor combinations for the treatment of bacteremia due to extended-spectrum beta-lactamase-producing Escherichia coli: a post hoc analysis of prospective cohorts. Clin Infect Dis. 2012;54:167-74. DOI:10.1093/cid/ cir790

26. Paterson DL, Bonomo RA. Extended-spectrum beta-lactamases: a clinical update. Clin Microbiol Rev. 2005;18:657-86. DOI: 10.1128/CMR.18.4.657-686.2005. 